\title{
A New Tool for Transbronchial Cryobiopsies in the Lung: An Experimental Feasibility ex vivo Study
}

\author{
Karl-Josef Franke ${ }^{a}$ Walter Linzenbold ${ }^{b}$ Daniela Nuessle ${ }^{b}$ Markus Enderle ${ }^{b}$ \\ Hans Boesmueller $^{c}$ Georg Nilius ${ }^{\text {a }}$ Jürgen Hetzel ${ }^{d}$ \\ ${ }^{a}$ Department of Pneumology and Critical Care Medicine, Helios Klinik Ambrock, Witten/Herdecke University, \\ Hagen, ${ }^{b}$ ERBE Research, ${ }^{c}$ Institute of Pathology and Neuropathology, University of Tübingen, and ${ }^{\mathrm{d}}$ Department of \\ Oncology, Hematology, Immunology, Rheumatology and Pulmonology, University Hospital, Internal Medicine II, \\ University of Tübingen, Tübingen, Germany
}

\section{For editorial comment see p. 204}

\section{Key Words}

Interstitial lung diseases · Transbronchial biopsy · Forceps biopsy · Cryobiopsy · Histology · Ex vivo lung model

\section{Abstract \\ Background: Transbronchial cryobiopsy (TBCB) is a mini- mally invasive procedure to establish a diagnosis of intersti- tial lung disease though with the disadvantage that samples have to be extracted together with the bronchoscope. $\mathbf{O b}$ - jectives: The aim of the present study was to evaluate the feasibility of a new cryoprobe with which biopsy samples can be obtained through the working channel of the flexible bronchoscope. Methods: The feasibility of obtaining trans- bronchial specimens with TBCB was tested and the tech- nique was compared to transbronchial forceps biopsy (TBFB) in a prospectively randomized ex vivo animal study using a standard flexible bronchoscopy technique. The rate of suc- cessful biopsies and the duration of the sampling procedure were recorded for both methods. Size and quality of the bi- opsies were histologically evaluated and measured. Results: Biopsy samples could be obtained in $93.3 \%$ of TBCB and in $79.0 \%$ of TBFB procedures $(p=0.182)$. Sampling procedure}

time did not differ in any clinically relevant manner between the two methods. The mean specimen area of TBCB samples was significantly higher compared to that of TBFB samples $\left(8.08 \pm 5.80\right.$ vs. $\left.2.61 \pm 2.14 \mathrm{~mm}^{2} ; p<0.0001\right)$. TBCB specimens showed less artifacts and a significantly higher percentage of alveolar tissue (53.57 vs. $25.42 \% ; p=0.0285$ ) than TBFB specimens. Conclusions: It is feasible to retrieve TBCB samples of good quality and size with the new mini cryoprobe through the working channel of the bronchoscope, while the bronchoscope remains within the central airways throughout the whole procedure. Further studies are necessary to evaluate the safety and efficacy in an in vivo setting.

(c) 2016 S. Karger AG, Basel

\section{Introduction}

The group of interstitial lung diseases (ILDs) consists of a great variety of entities, and multidisciplinary boards are regarded as the most appropriate approach to confidently achieve a final diagnosis $[1,2]$. Histology is required if clinical and radiological information do not allow a definitive diagnosis. Surgical lung biopsy (SLB) pro-

\section{KARGER}

E-Mail karger@karger.com

www.karger.com/res
C 2016 S. Karger AG, Basel

$0025-7931 / 16 / 0913-0228 \$ 39.50 / 0$
Karl-Josef Franke, MD

Department of Pneumology and Critical Care Medicine

Helios Klinik Ambrock, Witten/Herdecke University, Chair of Internal Medicine I

Ambrocker Weg 60, DE-58091 Hagen (Germany)

E-Mail karl-josef.franke@helios-kliniken.de 
vides large specimens, but is an invasive procedure with a fairly high risk, particularly in patients with advanced diseases and comorbidities as well as in the elderly. The rate of nonlethal complications of SLB is up to $18.1 \%$, and the overall 30 -day mortality is up to $4.3 \%$ in patients with idiopathic interstitial pneumonias [3]. Moreover, the spectrum of SLB to yield a final diagnosis is wide and ranges between 42 and 100\% [4-6]. To meet the heterogeneity in the histological pattern of lungs with ILD, multisite and multilobe biopsies are required, a challenge seldom complied with in clinical practice $[6,7]$.

Transbronchial lung biopsy (TBLB) is a more minimally invasive procedure than SLB to establish a histological diagnosis of ILD. However, TBLB performed as transbronchial forceps biopsy (TBFB) only provides small samples characterized by a number of artifacts, e.g. crush artifacts and telescoping of vessels [8]. Furthermore, TBFB fails to penetrate the wall of the peripheral airway and tissue obtained by TBFB is representative mainly for the centrilobular zone [9]. Therefore, TBFB achieves a comparatively high yield in ILDs with centrilobular presentation and/or specific pathological features like granulomatous or malignant diseases, while TBFB has a lower diagnostic yield for most of the ILDs characterized by a histological pattern across the lung and with the need to obtain preferably alveolar tissue [1, $10,11]$.

A new method to perform TBLB is transbronchial cryobiopsy (TBCB) using the cryoadhesion effect: lung tissue adheres to the distal end of the cryoprobe allowing the immediate extraction of samples [12]. The area of TBCBs of the lung is larger compared to the size of samples obtained by forceps [13-17]. The specimens of the cryobiopsy are of a high quality with less artifacts, contain more alveolar tissue [14,16-18] and result in a higher diagnostic yield for ILDs with a complex morphologic pattern like usual interstitial pneumonia and nonspecific interstitial pneumonia compared to the forceps biopsy $[13,18-21]$.

While the majority of studies report no major complications of TBCB, pneumothorax was reported in four studies with a frequency between 8 and $28 \%$ - the latter study only included patients with fibrotic diffuse parenchymal lung disease $[18,20,22,23]$. Furthermore, because bleeding is a not negligible risk of TBCB $[18,22,23]$, the possibility to leave the bronchoscope in the airway after performing TBCB would be an advantage.

Up to now, the tissue sample adhering to the cryoprobe cannot be retracted through the working channel of the bronchoscope but must be removed together with the endoscope, implying the need for a translaryngeal intubation or the need to perform rigid bronchoscopy.

Therefore, a new cryoprobe with the advantage to retract the specimen by means of an over-sheath through the working channel of the bronchoscope has been investigated in this study. The new probe is smaller in diameter, promising a very low complication rate but without the lack of a high diagnostic yield [12].

In the present ex vivo animal study, we investigated the feasibility of the new mini cryoprobe. The primary aim was to evaluate the retrieval rate of the mini cryoprobe in comparison with a standard forceps. Secondary aims were to evaluate the size and the quality of the TBCB specimens compared with TBFB specimens, the ease of use and handling of the cryoprobe, the sampling procedure time, and the functionality of the over-sheath of the cryoprobe.

\section{Materials and Methods}

The study was an ex vivo animal study. The experiments were performed in accordance with the federal law regarding the protection of animals. There was no need for an approval of the governmental review board.

\section{Equipment}

Two fresh and healthy swine lungs were obtained from the nearby slaughter house and used as a lung model for the ex vivo experiment. One at the time, the lungs were placed in an incubator and held at a constant temperature of $25^{\circ} \mathrm{C}$. The lungs were not perfused but ventilated with a pump set at $160-200 \mathrm{~mm} \mathrm{Hg}$. A flexible bronchoscope (EB 1975K, Pentax) was used to obtain a transbronchial biopsy using either a standard biopsy forceps (alligator forceps, diameter $1.8 \mathrm{~mm}$, Boston Scientific, Malborough, Mass., USA) or a newly developed mini cryoprobe with a diameter of 1.1 $\mathrm{mm}$ (ERBE Elektromedizin $\mathrm{GmbH}$ ) used in conjunction with a 2.6-mm over-sheath that serves as a protection tube for the working channel of the bronchoscope (fig. 1). When compared with the small new cryoprobe with an outer diameter of $1.1 \mathrm{~mm}$, the 1.8 $\mathrm{mm}$ alligator forceps was chosen because similar-sized tissue samples could be obtained to those with a forceps with a bigger cup.

Cooling of the cryoprobe, using $\mathrm{CO}_{2}$ as the cooling agent, was initiated by pressing the foot pedal of the cryo unit (ERBECRYO2, ERBE Elektromedizin $\mathrm{GmbH}$ ) for an activation time of 2, 3, 4, 5 and $6 \mathrm{~s}$.

\section{Procedure}

TBFB samples were obtained in the standard fashion. The forceps was passed through the working channel of the bronchoscope and the biopsy samples were removed together with the forceps through the working channel, thereby leaving the bronchoscope in the respiratory tract.

In case of TBCB, the over-sheath was passed through the working channel of the bronchoscope and connected to the bronchoscope by a Luer Lock. While the sheath itself stays mainly inside 


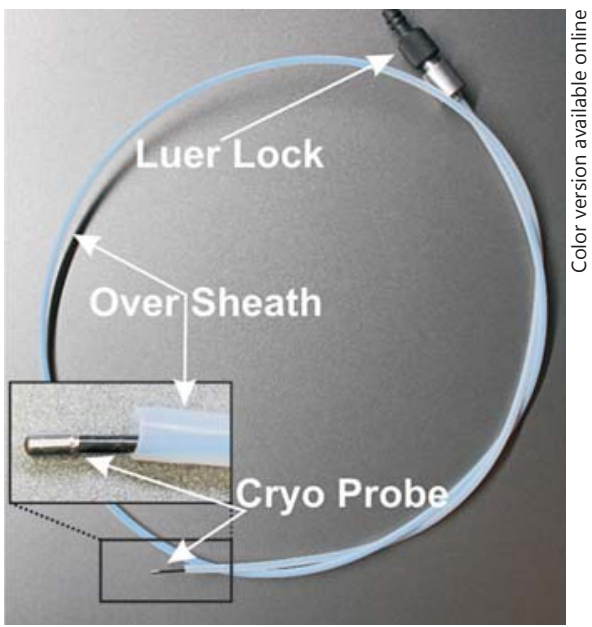

Fig. 1. Overview of the new mini cryoprobe with a diameter of 1.1 $\mathrm{mm}$ used in combination with a $2.6-\mathrm{mm}$ over-sheath that serves as a protection tube for the working channel of a bronchoscope. The over-sheath is passed through the working channel of the bronchoscope and connected by a Luer Lock, staying in place over the whole sampling procedure.

the bronchoscope, the distal tip of the sheath is only projected approximately $3 \mathrm{~mm}$ beyond the distal tip of the bronchoscope.

The cryoprobe was advanced through the over-sheath to the target position and the activating pedal was pressed continuously. At the specified activation time, a quick and jerky movement to the cryoprobe was applied and was then removed together with the attached biopsy through the over-sheath, thereby leaving the bronchoscope together with the connected over-sheath in place. The activation of the cryounit was maintained until the biopsy was entirely outside the bronchoscope.

All biopsies were obtained under direct visual and haptic control; i.e., the cryoprobe or the forceps was advanced into the bronchus until it reached either the maximum possible position or the pleura. If the pleura was reached, both instruments were pulled back for approximately $10 \mathrm{~mm}$ and a biopsy was obtained from one of the four possible positions, i.e. right (lower and upper) and left (lower and upper) lobes, respectively.

The site of the biopsy, i.e. right (lower and upper) or left (lower and upper), the choice of the instrument and, in case of the cryoprobes, also the activation time were randomly assigned. A minimum of 6 biopsies were obtained with the cryoprobes using each activation time. The number of biopsies using the standard forceps was restricted to not more than 20 samples. The yielded samples were placed on a plastic strip immediately after retrieval and weighed using a precision balance before the preservation in formalin. The precision balance was tared with the plastic strip beforehand. The samples were weighed to obtain additional information on the size of the biopsies, other than the area measured microscopically.

For each biopsy, the number of attempts to acquire a sample and the duration of the sampling procedure were recorded. The duration of the sampling procedure for TBFB and TBCB was cal- culated by the difference between the time starting with the opening of the forceps or, in case of the cryoprobe, with the activation of the probe and the time until the instruments were extracted from the bronchoscope.

\section{Specimen Processing and Evaluation}

All biopsy specimens were fixed in formalin, embedded in paraffin blocks and stained with hematoxylin and eosin for the evaluation of the total sample area $\left(\mathrm{mm}^{2}\right)$, alveolated area $\left(\mathrm{mm}^{2}\right)$, percent of artifact-free lung parenchyma and presence of crush artifact by a dedicated lung pathologist. All biopsy specimens were assessed by a pathologist who was blinded to the biopsy method. Samples were declared as good-quality samples, potentially leading to diagnosis, if:

- alveoli were present and the alveolar area was big enough to potentially diagnose (size and amount);

- there were no crush artifacts or an amount of crush artifacts which still allowed for potential diagnosis;

- the assessment of the relevant morphological and histological structures and features were at least possible despite a limitation in specimen quality.

\section{Statistical Analysis}

All data were analyzed using GraphPad 6 (GraphPad Software Inc.). Continuous variables are presented as means and standard deviations (SD). $\chi^{2}$ testing was used when comparing proportions. An ordinary one-way analysis of variance (ANOVA) or, in case of a nonparametric test, the Kruskal-Wallis test with post hoc multiple comparisons was used to evaluate differences between groups. The Student t test was used to compare mean differences of two groups. A p value $<0.05$ was considered significant.

\section{Results}

In total, 45 attempts were made to obtain 42 (retrieval rate: $93.33 \%$ ) specimens using cryoprobes (TBCB) and 19 attempts to obtain 15 (retrieval rate: $78.95 \%)$ specimens $(\mathrm{p}=0.18)$ using forceps (TBFB). In 2 cases (4-second activation) of TBCB, no visible specimen was detected on the tip of the probe while in 1 case (6-second activation), the specimen was too big to be retracted into the oversheath.

The mean weight of the samples revealed a significant difference between TBFB and TBCB for activation times higher than $2 \mathrm{~s}$ in favor of the cryoprobe (fig. 2). The sample weights increased with increasing cryoactivation time $(\mathrm{p}=0.0097)$ showing a clear positive correlation $(\mathrm{R}=$ $0.66)$.

\section{Sampling Procedure Time}

The mean sampling procedure time for the TBFB was $6.5 \mathrm{~s}$ (SD: 1.2). The times for the TBCB increased with increasing activation time and lasted between $4.3 \mathrm{~s}$ for an activation time of $2 \mathrm{~s}$ and $7.75 \mathrm{~s}$ for an activation time of 


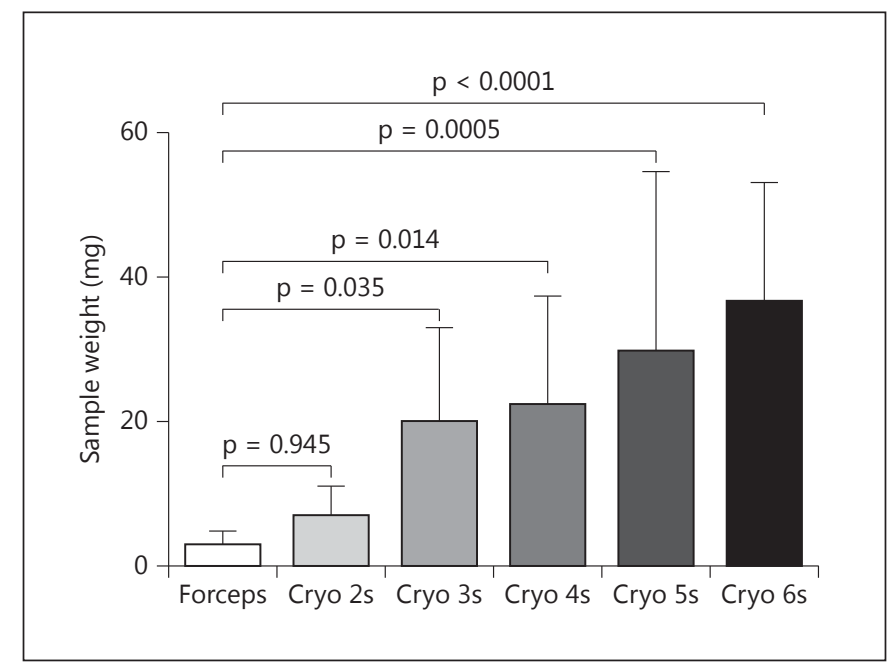

Fig. 2. Sample weights comparing transbronchial biopsy with forceps and the mini cryoprobe using activation times between 2 and $6 \mathrm{~s}$ (Cryo 2s-Cryo 6s). The biopsy weight increases with the activation time $(\mathrm{R}=0.66)$.

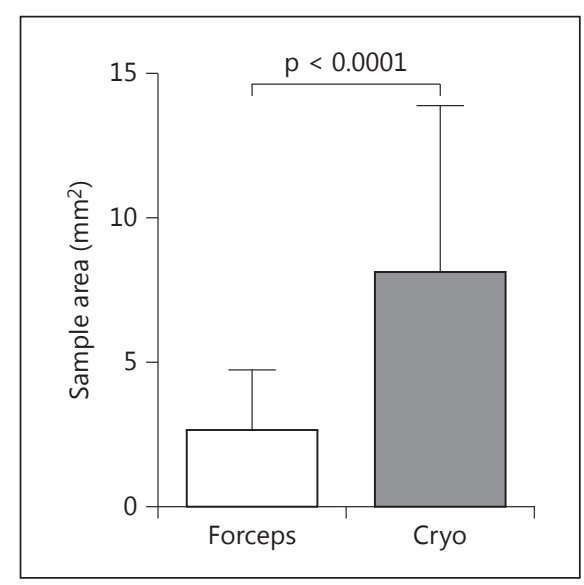

Fig. 4. Sample area of forceps biopsy and cryobiopsy. The data for the cryobiopsy were pooled over all activation times.

$6 \mathrm{~s}$ (fig. 3). Compared to the forceps, activation times of $2 \mathrm{~s}(\mathrm{p}<0.0001)$ and $3 \mathrm{~s}(\mathrm{p}=0.0008)$ significantly lowered the sampling time while an activation time of $6 \mathrm{~s}(\mathrm{p}<$ 0.025) significantly increased the sampling time (fig. 2).

\section{Histology}

A total of $25 \%$ of the biopsies obtained by TBFB and $57.14 \%$ obtained by TBCB were of good quality. The mean specimen area of the samples was $2.61 \mathrm{~mm}^{2}$ (SD:

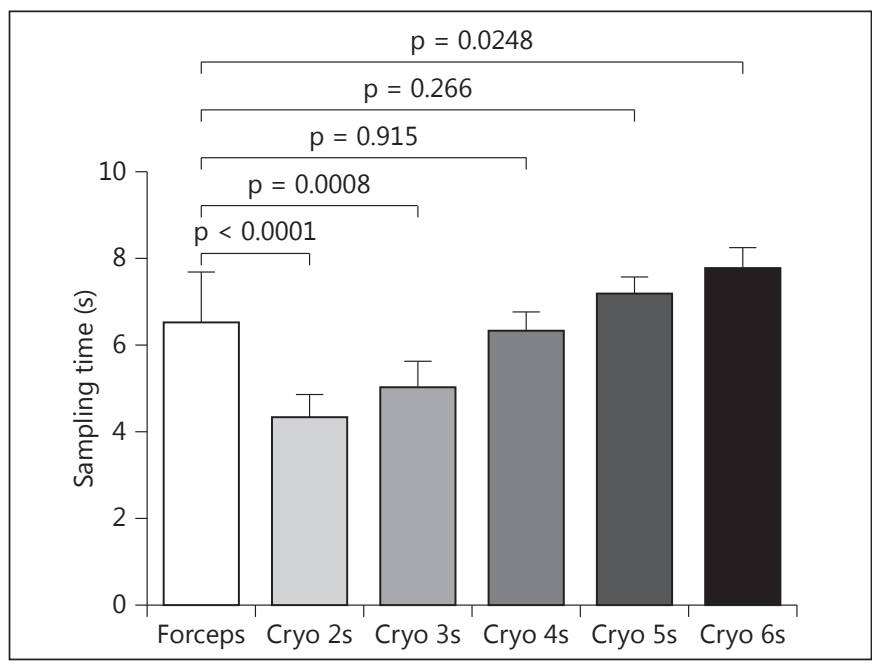

Fig. 3. Sampling procedure time comparing transbronchial biopsy with forceps and the cryoprobe using activation times between 2 and $6 \mathrm{~s}$ (Cryo 2s-Cryo 6s).
2.14) for forceps compared with $8.08 \mathrm{~mm}^{2}$ (SD: 5.80) for TBCB ( $<<0.0001$; fig. 4).

The mean specimen area of samples that were declared as good-quality biopsies was $8.36 \mathrm{~mm}^{2}$ (SD: 4.38) for TBCB and $4.067 \mathrm{~mm}^{2}$ (SD: 3.77) for TBFB ( $<<0.0879$ ).

The average percentage of alveolar tissue for the forceps samples $(25.42 \%)$ was significantly lower compared with the $53.57 \%$ for the TBCB samples ( $\mathrm{p}=0.0285)$.

On average, $80.95 \%$ of the total area of the TBCB and $66.66 \%$ of the TBFB specimens had over $75 \%$ unaltered tissue area, i.e. no or just little crush artifacts (fig. 5).

\section{Discussion}

A vast amount of publications in the last few years have demonstrated the high quality and diagnostic yield of cryobiopsy during flexible, endobronchial and transbronchial biopsies using conventional cryoprobe with di-

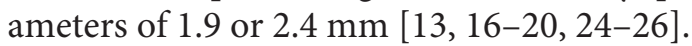

One major disadvantage of the standard cryobiopsy is that it cannot be retracted through the working channel of the endoscope but must be removed together with the endoscope en bloc. Although extraction of cryobiopsies with the bronchoscope using a flexible or a rigid tube is easy, a new probe which allows retracting the specimen through the working channel of the endoscope would be a significant improvement in handling and use. There- 
Fig. 5. Example of a biopsy obtained by a cryoprobe and a standard forceps. Cryobiopsy samples were larger than the forceps biopsies and contained fewer crush artifacts than the standard forceps. All specimens were fixed in formalin, embedded in paraffin blocks and stained with hematoxylin and eosin.

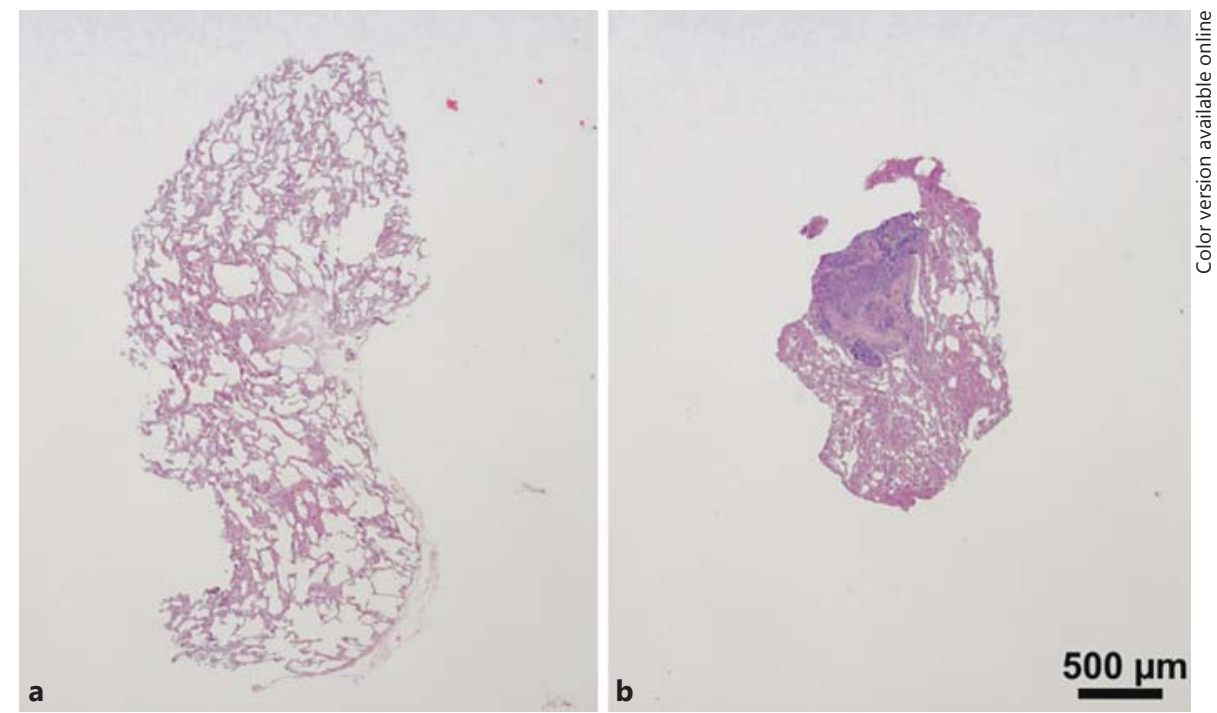

fore, the current study aimed to demonstrate the feasibility to obtain transbronchial biopsies from fresh animal cadaver lungs using a newly developed cryoprobe (TBCB) with a diameter of $1.1 \mathrm{~mm}$, which allows to extract biopsy samples through an over-sheath placed into the working channel of the endoscope, and compared the results to a standard forceps biopsy (TBFB). The activation times (2-6 s) of the new cryoprobe used in our study were adjusted to the activation times of standard cryoprobes reported in the literature (3-6 s) [13-15, 17-20, 25]. The present study clearly demonstrates the feasibility to yield TBCB samples with the new mini cryoprobe.

Specimens obtained with TBCB were significantly heavier compared to those obtained with TBFB by a factor of $2-10$, depending on the activation time of the cryoprobe. Activation times of $2 \mathrm{~s}$ yielded smaller biopsies than activation times of $6 \mathrm{~s}$. This relationship between the weight of the specimens and the activation time has been demonstrated in previous studies [12, 27, 28]. Although the weight of a specimen can be regarded as a good indicator for the size of a specimen, it does not directly reflect the quality of a specimen. The weight can be affected by several factors like high fluid or cartilage content and should therefore be treated with caution. The quality of a biopsy sample can better be assessed by histological and morphological evaluation of the specimen.

The area of the TBCB specimens was more than three times larger than the area of samples obtained by TBFB. The ratio 3:1 between TBCB and TBFB is similar to previous reports in clinical studies using standard cryoprobes $[13,15-18]$, although the absolute numbers are different.
While studies using the standard cryoprobes report mean areas between 9 and $64 \mathrm{~mm}^{2}$ and corresponding mean areas of forceps biopsy samples between 2 and $12.5 \mathrm{~mm}^{2}$ $[13,17,19,29]$, our results were at the lower end of these ranges for both TBCB $\left(8.08 \pm 5.80 \mathrm{~mm}^{2}\right)$ and TBFB (2.61 $\pm 2.14 \mathrm{~mm}^{2}$ ). The smaller size of the sample area obtained with TBCB compared to a standard cryoprobe can be explained by the smaller outer diameter of the probe, which is far smaller as a standard cryoprobe and is limited by the inner diameter of the over-sheath. However, this cannot explain the results for the forceps biopsies. One explanation of the difference between the results of the clinical studies and our results is that there is a difference between the clinical human setting and an ex vivo animal lung model. This has to be evaluated further in clinical trials. There was only one biopsy sample that could not be retracted through the over-sheath because of its large size. This indicates that there is an upper limitation of the size of TBCB specimens obtained by a maximum activation time of 6-8 s with the new cryoprobe, at least in our lung model.

With regard to morphological and histological quality, $57.14 \%$ of in vitro TBCB specimens and only $25 \%$ of TBFB specimens were scored as good quality.

The percentage of alveolar tissue for TBCB (53.57\%) was more than twice as high as for TBFB (25.42\%). Similar results have been reported in recent clinical trials with the standard cryoprobe in transbronchial biopsies. Both, Yarmus et al. [17] and Fruchter et al. [16] compared the biopsy results taken with either cryobiopsy or forceps biopsy in patients after lung transplantation. Their results 
showed a significant difference between the two techniques in terms of the percentage of alveolar tissue in favor of the cryobiopsy with more than twice as much alveolar tissue than the forceps biopsy. The cryobiopsy samples did not contain any crush artifacts, while all forceps biopsies were affected by such artifacts. Although their results are in good agreement with the vast majority of previous clinical studies using cryotechnique, this finding is contrary to our results where both, TBCB and TBFB samples contained crush artifacts. One could hypothesize that the use of an over-sheath might influence the quality of the biopsy and evokes crush artifacts due to the narrow space between cryoprobe and the over-sheath.

Such an influence on the quality of the specimens has been studied in an animal model using a cryoneedle without an over-sheath and with different over-sheath diameters for pancreas biopsies [30]. Although there was a limitation of the specimen size for the different sheath diameters, there was no significant difference in artifacts between the use of the cryoneedle without and with different over-sheath diameters [30]. Therefore, it is unlikely that the artifacts of TBCB were caused merely by the over-sheath and they could also be a side effect of the here used animal lung model.

The sampling procedure time of TBCB versus TBFB did not differ in any clinically relevant manner. One previous clinical study investigated amongst other parameters the diagnostic yield of endobronchial cryobiopsy as well as the time needed for biopsy and subsequent bleeding control for cryobiopsy and forceps biopsy [24]. The results showed no significant difference between both techniques with respect to the time needed, with just a trend towards a longerlasting cryobiopsy procedure [24]. However, patients were intubated with a flexible tube or a rigid bronchoscope before performing flexible bronchoscopy and cryobiopsy. In contrast, a flexible TBCB can be performed directly through an over-sheath without the need for a rigid instrument, which may shorten the overall procedure.

Our study has some limitations: first, our ex vivo animal lung model was not perfused and this may have had a significant influence on the results. Second, our lung model was not pathologic and, therefore, we could only estimate the potential diagnostic yield and evaluated the quality of the specimens via a semi-quantitative score. Moreover, our model does not allow any assessment of the risk of TBCB with the new cryoprobe. Finally, although the study was randomized in design and the pathologists were formally blinded concerning the sampling technique, the blinding could have been ineffective due to the obvious difference in sampling size.

\section{Conclusion}

It is feasible to retrieve TBCB samples with the new mini cryoprobe. Furthermore, transbronchial biopsies performed with the new mini cryoprobe with an oversheath provide significantly larger specimens of high quality compared to standard forceps biopsy in this animal model. The major advantage of the new probe is that it can be used through the working channel in a flexible way without the need of a rigid tube or intubation, which makes the procedure easier and more minimally invasive compared to standard cryobiopsy. Up to now, we cannot draw any conclusion with respect to safety and true diagnostic yield of the new cryoprobe. Further in vivo animal and clinical studies are necessary to prove the safety and efficacy of the new cryoprobe.

\section{Statement of Ethics}

The study was an ex vivo animal study. The experiments were performed in accordance with the federal law regarding the protection of animals. There was no need for an approval of the governmental review board.

\section{Financial Disclosure and Conflicts of Interest}

Karl-Josef Franke, Hans Boesmueller, Georg Nilius and Jürgen Hetzel declare that they have no financial involvement in the subject discussed in the submitted manuscript and that they have no conflict of interest. Walter Linzenbold, Daniela Nuessle and Markus Enderle are employees at ERBE Germany.

References

1 Bradley B, Branley HM, Egan JJ, Greaves MS, Hansell DM, Harrison NK, Hirani N, Hubbard R, Lake F, Millar AB, Wallace WA, Wells AU, Whyte MK, Wilsher ML; British Thoracic Society Interstitial Lung Disease Guideline Group, British Thoracic Society Standards of Care Committee; Thoracic Society of Australia; New Zealand Thoracic Society; Irish Thoracic Society: Interstitial lung disease guideline: the British Thoracic Society in collaboration with the Thoracic Society of Australia and New Zealand and the Irish Thoracic Society. Thorax 2008;63(suppl 5):v1-v58, erratum in Thorax 2008;63:1029.

$\checkmark 2$ Deconinck B, Verschakelen J, Coolen J, Verbeken E, Verleden G, Wuyts W: Diagnostic workup for diffuse parenchymal lung disease: schematic flowchart, literature review, and pitfalls. Lung 2013;191:19-25. 
-3 Nguyen W, Meyer KC: Surgical lung biopsy for the diagnosis of interstitial lung disease: a review of the literature and recommendations for optimizing safety and efficacy. Sarcoidosis Vasc Diffuse Lung Dis 2013;30:3-16.

4 Lee YC, Wu CT, Hsu HH, Huang PM, Chang YL: Surgical lung biopsy for diffuse pulmonary disease: experience of 196 patients. J Thorac Cardiovasc Surg 2005;129:984-990.

-5 Qureshi RA, Stamenkovic SA, Carnochan FM, Walker WS: Video-assisted thoracoscopic lung biopsy in patients with interstitial lung disease. Ann Thorac Surg 2007;84:21362137.

6 Blackhall V, Asif M, Renieri A, Civitelli S, Kirk A, Jilaihawi A, Granato F: The role of surgical lung biopsy in the management of interstitial lung disease: experience from a single institution in the UK. Interact Cardiovasc Thorac Surg 2013;17:253-257.

-7 Travis WD, Costabel U, Hansell DM, King TE Jr, Lynch DA, Nicholson AG, Ryerson CJ, Ryu JH, Selman M, Wells AU, Behr J, Bouros D, Brown KK, Colby TV, Collard HR, Cordeiro CR, Cottin V, Crestani B, Drent M, Dudden RF, Egan J, Flaherty K, Hogaboam C, Inoue Y, Johkoh T, Kim DS, Kitaichi M, Loyd J, Martinez FJ, Myers J, Protzko S, Raghu G, Richeldi L, Sverzellati N, Swigris J, Valeyre D; ATS/ ERS Committee on Idiopathic Interstitial Pneumonias: An official American Thoracic Society/European Respiratory Society statement: update of the international multidisciplinary classification of the idiopathic interstitial pneumonias. Am J Respir Crit Care Med 2013;188:733-748.

8 Colby TV: The pathologist's approach to bronchoscopic biopsies. Pathologica 2010; 102:432-442.

-9 Poletti V, Casoni GL, Gurioli C, Ryu JH, Tomassetti S: Lung cryobiopsies: a paradigm shift in diagnostic bronchoscopy? Respirology 2014;19:645-654.

10 Descombes E, Gardiol D, Leuenberger P: Transbronchial lung biopsy: an analysis of 530 cases with reference to the number of samples. Monaldi Arch Chest Dis 1997;52: 324-329.

-11 Tomassetti S, Cavazza A, Colby TV, Ryu JH, Nanni O, Scarpi E, Tantalocco P, Buccioli M, Dubini A, Piciucchi S, Ravaglia C, Gurioli C, Casoni GL, Gurioli C, Romagnoli M, Poletti $\mathrm{V}$ : Transbronchial biopsy is useful in predicting UIP pattern. Respir Res 2012;13:96.
12 Franke K-J, Szyrach M, Nilius G, Hetzel J, Hetzel M, Ruehle KH, Enderle MD: Experimental study on biopsy sampling using new flexible cryoprobes: influence of activation time, probe size, tissue consistency, and contact pressure of the probe on the size of the biopsy specimen. Lung 2009;187:253-259.

13 Babiak A, Hetzel J, Krishna G, Fritz P, Moeller P, Balli T, Hetzel M: Transbronchial cryobiopsy: a new tool for lung biopsies. Respiration 2009;78:203-208.

14 Pajares V, Torrego A, Puzo C, Lerma E, Gil De Bernabé MA, Franquet T: Transbronchial lung biopsy using cryoprobes. Arch Bronconeumol 2010;46:111-115.

15 Griff S, Ammenwerth W, Schönfeld N, Bauer TT, Mairinger T, Blum TG, Kollmeier J, Grüning W: Morphometrical analysis of transbronchial cryobiopsies. Diagn Pathol 2011;6:53.

16 Fruchter O, Fridel L, Rosengarten D, Raviv Y, Rosanov V, Kramer MR: Transbronchial cryo-biopsy in lung transplantation patients: first report. Respirology 2013;18:669-673.

17 Yarmus L, Akulian J, Gilbert C, Illei P, Shah P, Merlo C, Orens J, Feller-Kopmann D: Cryoprobe transbronchial lung biopsy in patients after lung transplantation: a pilot safety study. Chest 2013;143:621-626.

18 Pajares V, Puzo C, Castillo D, Lerma E, Montero MA, Ramos-Barbón D, Amor-Carro O, Gil de Bernabé A, Franquet T, Plaza V, Hetzel J, Sanchis J, Torrego A: Diagnostic yield of transbronchial cryobiopsy in interstitial lung disease: a randomized trial. Respirology 2014; 19:900-906.

19 Kropski JA, Pritchett JM, Mason WR, Sivarajan L, Gleaves LA, Johnson JE, Lancaster LH, Lawson WE, Blackwell TS, Steele MP, Loyd JE, Rickman OB: Bronchoscopic cryobiopsy for the diagnosis of diffuse parenchymal lung disease. PLoS One 2013;8:e78674.

20 Casoni GL, Tomassetti S, Cavazza A, Colby TV, Dubini A, Ryu JH, Carretta E, Tantalocco P, Piciucchi S, Ravaglia C, Gurioli C, Romagnoli M, Gurioli C, Chilosi M, Poletti V: Transbronchial lung cryobiopsy in the diagnosis of fibrotic interstitial lung diseases. PLoS One 2014;9:e86716.

21 Griff S, Schönfeld N, Ammenwerth W, Blum TG, Grah C, Bauer TT, Grüning W, Mairinger T, Wurps H: Diagnostic yield of transbronchial cryobiopsy in non-neoplastic lung disease: a retrospective case series. BMC Pulm Med 2014;14:171.
22 Hernández-González F, Lucena CM, Ramírez J, Sánchez M, Jimenez MJ, Xaubet A, Sellares J, Agustí C: Cryobiopsy in the diagnosis of diffuse interstitial lung disease: yield and costeffectiveness analysis. Arch Bronconeumol 2015;51:261-267.

23 Hagmeyer L, Theegarten D, Wohlschläger J, Treml M, Matthes S, Priegnitz C, Randerath WJ: The role of transbronchial cryobiopsy and surgical lung biopsy in the diagnostic algorithm of interstitial lung disease. Clin Respir J 2015, Epub ahead of print.

24 Hetzel J, Eberhardt R, Herth FJ, Petermann C, Reichle G, Freitag L, Dobbertin I, Franke KJ Stanzel F, Beyer T, Möller P, Fritz P, Ott G, Schnabel PA, Kastendieck H, Lang W, Morresi-Hauf AT, Szyrach MN, Muche R, Shah PL, Babiak A, Hetzel M: Cryobiopsy increases the diagnostic yield of endobronchial biopsy: a multicentre trial. Eur Respir J 2012;39:685690.

25 Fruchter O, Fridel L, Rosengarten D, Rahman NA, Kramer MR: Transbronchial cryobiopsy in immunocompromised patients with pulmonary infiltrates: a pilot study. Lung 2013; 191:619-624.

26 Schuhmann M, Bostanci K, Bugalho A, Warth A, Schnabel PA, Herth FJ, Eberhardt R: Endobronchial ultrasound-guided cryobiopsies in peripheral pulmonary lesions: a feasibility study. Eur Respir J 2014;43:233-239.

27 Franke K-J, Theegarten D, Hann von Weyhern C, Nilius G, Brueckner C, Hetzel J, Hetzel M, Ruhle KH, Enderle MD, Szyrach M: Prospective controlled animal study on biopsy sampling with new flexible cryoprobes versus forceps: evaluation of biopsy size, histological quality and bleeding risk. Respiration 2010;80:127-132.

28 Franke KJ, Nilius G, Ruehle KH, Enderle MD, Linzenbold W, Hann von Weyhern C: The cryo-needle: a new tool for histological biopsies. A feasibility study. Lung 2013;191:611617.

29 Fruchter O, Fridel L, El Raouf BA, AbdelRahman N, Rosengarten D, Kramer MR: Histological diagnosis of interstitial lung diseases by cryo-transbronchial biopsy. Respirology 2014;19:683-688.

- 30 Von Renteln D, Quaas A, Rösch T, Denzer UW, Szyrach MN, Enderle MD, Lüth S, Haas S, Trepte C, Reutter D, Schachschal G: A novel flexible cryoprobe for EUS-guided pancreatic biopsies. Gastrointest Endosc 2013;77: 784-792. 